\title{
ALGUNOS POEMAS INÉDITOS DE BLAS DE OTERO CORRESPONDIENTES A LA PRIMERA ETAPA DE SU CREACIÓN
}

Lucía Montejo GurRuchaga

UNED. Madrid

lmontejo@flog.uned.es

\section{RESUMEN}

Los diez poemas inéditos que muestro en este artículo forman parte de los manuscritos de sus obras Ángel fieramente humano, Redoble de conciencia y Ancia y pertenecen, por tanto, a su primera etapa. Otero los entregó en la Sección de Inspección de Libros, como era preceptivo, para solicitar la tarjeta de autorización para su publicación.

Algunos son de tema amoroso, otros reflejan la condición mortal del hombre, la angustia existencial de una humanidad en ruinas En otros irrumpe el tema histórico, la tragedia colectiva de la guerra y el compromiso del poeta con el hombre. En ellos se detectan algunas de las características de su poesía, como el virtuosismo con que maneja el soneto, el rendimiento sorprendente y eficaz que saca de los recursos expresivos o la presencia de algunos autores que siempre le han acompañado.

Palabras Clave: Blas de Otero, inéditos, primera etapa.

\section{ABSTRACT}

The ten unedited poems in this paper are part of Blas de Otero's manuscripts of Ángel fieramente humano, Redoble de conciencia y Ancia, so they belong to his first period. Otero submitted them to the Book Inspection Section (Sección de Inspección de Libros) as he was bound to do in order to get the authorisation card for publication. 
Some of them are love poems, others reflect man's mortal condition, the existential anguish because of a humankind in ruins. The historical subject, war collective tragedy and the engagement of the poet with man bursts into some. In these poems we can detect some of his poetry characteristics, the mastery in dealing with sonnets, the surprisingly high yield he gets of expressive resources or the presence of some authors who have always accompanied him.

KeY Words: Blas de Otero; unpublished; first works.

La crítica oteriana ha puesto de manifiesto en muchas ocasiones la incesante reelaboración a la que el poeta sometía sus composiciones no dándolas nunca por terminadas. En las sucesivas reediciones corrige versos, cambia el orden de los poemas, modifica títulos, elimina poemas que, a veces, añade a otro libro, y como consecuencia de esta manipulación constante encontramos variantes en las reediciones y en las antologías. El poeta vasco publica antologías desde muy temprano, con frecuencia para paliar las dificultades económicas que ha de afrontar a causa de la censura, y la anticipación en ellas de poemas inéditos que se integrarán más tarde en libro independiente, es uno de sus rasgos peculiares y de suma importancia para el estudio de la génesis textual, porque casi siempre ofrecen variantes respecto a la redacción definitiva.

En un trabajo reciente, Jauralde Pou hace notar la urgente necesidad de una edición completa y definitiva de la obra de Otero, porque la continua reelaboración y su muerte temprana han propiciado que «la obra quedara como flotando, no inconclusa, sino indeterminada para lo que un historiador o un filólogo hubiera deseado. Un puñado de libros, desguazados a veces para formar antologías y libros ocasionales, de carácter más temático que cronológico, otros dos anunciados y parcialmente publicados, pero todavía desconocidos; bastante obra dispersa, etc. La obra de Blas de Otero está pidiendo a gritos un trabajo histórico, biográfico y filológico que termine por darnos textos fiables, íntegros y cabalmente presentados y ordenados ${ }^{1} »$, una edición que desde hace tiempo se anuncia, que entraña, por todo lo expuesto, y como en distintas ocasiones ha expresado Sabina de la Cruz, grandes dificultades que esperamos y deseamos se resuelvan pronto ${ }^{2}$.

A esa corrección minuciosa a la que sometía sus composiciones, a ese trabajo constante hay que añadir el efecto, no menor, de la censura franquista en su obra. Otero fue muy castigado durante casi tres décadas, como he ido demostrando en los distintos trabajos que, sobre este asunto, vengo publicando desde $1996^{3}$. Este es un hecho de suma

${ }^{1}$ Blas de Otero, Antología poética. Edición de Pablo Jauralde Pou, Madrid, Castalia, 2007, p. 10. La selección, la introducción, que esclarece y actualiza vías de interpretación y las notas muy valiosas, hacen de esta antología un volumen imprescindible para el estudio de la obra del poeta.

2 Véase al respecto la antología Blas de Otero, Poesía escogida. Edición de Sabina de la Cruz y Lucía Montejo, Barcelona, Vicens-Vives, segunda edición (corregida), 2000, XLIII.

${ }^{3}$ Pueden verse mis artículos «Las limitaciones de expresión en España durante las décadas cincuenta y sesenta: el ejemplo de dos antologías poéticas», Epos, XII (1996), 277-295; «Blas de Otero y la censura española: la antología Verso y prosa (1973), Volver a Blas de Otero, Zurgai (julio 1998), 38-41; Blas de Otero y la censura española desde 1949 hasta la transición política: Primera parte: de Ángel fieramente humano a En castellano, Revista de Literatura, LX, 120 (1998), 491-513; «Blas de Otero y la censura española desde 1949 hasta la transición política. Segunda parte: de Que trata de España (1964) a Todos mis sonetos (1977), LXII, 123 (2000), 
importancia porque le forzará a publicar con mutilaciones y variantes —que corregirá, no en todos los casos, después de la transición política- para paliar las dificultades económicas que sufre por esta causa.

Desde que presenta a censura su primer manuscrito, el que corresponde a Ángel fieramente humano en 1949 hasta el final de su trayectoria creadora, algunos años después de la transición política, este órgano de control le entorpeció su labor durante más de dos décadas. Le forzó a autocensurarse, a introducir modificaciones en muchos poemas, a suprimir versos y poemas completos ${ }^{4}$. Le denegó la publicación de uno de sus libros - En castellano - en 1959, sin posibilidad de recurrir la sentencia, le retrasó más de un año la publicación del siguiente, de Que trata de España, y le empujó a publicar en el extranjero con el consiguiente perjuicio y no solamente económico ${ }^{5}$. Prohibió igualmente la importación de algunos de los libros que se había visto forzado a publicar en el extranjero ${ }^{6}$.

Ante tantas dificultades, además de reunir poemas en antologías, unas veces con criterio estético, por razones temáticas, para ofrecer una visión global de su trayectoria poética o para dar a conocer fuera de su país los poemas censurados, muestra también poemas inéditos, en muchos casos, en las distintas revistas literarias que van surgiendo por todo el país. Se propone, en primer lugar, dar a conocer a lectores y críticos su inmediata creación; en segundo lugar, sondear el comportamiento censor y, por último, ingresar unos escasos recursos que le permitan sobrevivir? ${ }^{7}$.

155-175; «Efectos de la censura en la obra de Blas de Otero. Recursos de la enunciación», Ancia. Revista de la Fundación Blas de Otero, II, 3 (2004), 15-31.

${ }^{4}$ Hay ejemplos interesantes de autocensura en Pido la paz y la palabra, porque como los editores tuvieron serias dudas de la viabilidad del proyecto, el poeta mutiló, suprimió, alteró y disfrazó muchos versos para poder conseguir la tarjeta de autorización para su publicación. Puede verse al respecto el libro de Julio Neira, Blas de Otero. Correspondencia sobre la edición de Pido la paz y la palabra, Madrid, Hiparión, 1987. Los ejemplos más claros y reiterados de autocensura están en En castellano, considerado por la crítica como su libro más político, aunque en mayor o menor grado tuvo que anular, modificar o rectificar poemas en todos sus libros, salvo en $R e$ doble de conciencia. En los artículos citados en la nota anterior hay ejemplos sobrados de autocensura.

${ }^{5}$ En agosto de 1958, la censura le deniega el permiso para la publicación de En castellano. Un año después, el editor Pierre Seghers editará el libro en París, en edición bilingüe, con el título Parler clair, traducido y prologado por el hispanista Claude Couffon. En 1960 será publicado por la Universidad Autónoma de México y casi al mismo tiempo, la editorial Losada de Buenos Aires, lo publicará en un volumen junto a Pido la paz y la palabra con el título de Con la inmensa mayoría. Esta misma editorial reunirá en un solo volumen, en 1962, los cuatro libros del poeta: Ángel fieramente humano, Redoble de conciencia, Pido la paz y la palabra y En castellano, con el título general de Hacia la inmensa mayoría.

${ }^{6}$ En el Archivo General de la Administración de Alcalá de Henares está el expediente en el que se solicita el permiso de importación del libro de Blas de Otero, Con la inmensa mayoría, publicado en Buenos Aires por Losada. Recoge sus libros Pido la paz y la palabra y En castellano. El censor informa que se trata de una colección de magníficos poemas, y a continuación puntualiza que «varios tienen un marcado carácter político». Como consecuencia, se prohíbe.

7 Algunos datos sobre la biografía del poeta durante esta década se pueden encontrar en los siguientes artículos de Sabina de la Cruz: «Notas biográficas de Blas de Otero», Al Amor de Blas de Otero. Edición a cargo de José Ángel Ascunce. Actas de las III Jornadas Internacionales de Literatura: Blas de Otero, San Sebastián, Universidad de Deusto, 1986, 21-35 y en «Los poetas del grupo catalán y Blas de Otero», Ínsula, 523-524 (julioagosto, 1990), 17-19.

${ }^{8}$ La revista Espadaña recogió en un número de 1950 el soneto «Déjame», que tantos problemas le dará en lo sucesivo: «Me haces daño, Señor. Quita tu mano/ de encima. Déjame con mi vacío,/ déjame. Para abismo, con el mío/ tengo bastante. Oh Dios, si eres humano,/ compadécete ya, quita esa mano/ de encima. No me sirve. Me da frío/ y miedo. Si eres Dios, yo soy tan mío/ como tú. Y a soberbio, yo te gano./ Déjame. ¡Si pudiese yo matarte ,/ como haces tú, como haces tú! Nos coges/ con las dos manos, nos ahogas. Matas/ no se sabe por qué. 
Sin embargo, no solo le acosó en sus propias publicaciones, sino que multó y reprendió a directores de publicaciones periódicas que acogieron algunos de sus poemas ${ }^{8}$. Su presencia en las revistas literarias fue incesante durante varias décadas. Desarrolla una gran actividad y sus poemas aparecen, entre otras, en Cisneros, Escorial, Ínsula, Corcel, La isla de los ratones, Espadaña, Poesía Española, Platero, Cántico, Mensajes de poesía, Papeles de Son Armadans, Caracola, Clavileño, Cuadernos Hispanoamericanos. Es un asiduo colaborador de algunas, como de Ínsula, a la que envía, durante treinta años, composiciones inéditas de todos sus libros, que serán publicadas sin autocensura, aunque no sin problemas 9 . Aunque la mayor parte de estos poemas pasaron, poco después de la publicación en estas revistas, a integrarse en el libro del que formaban parte, algunos no los recogió y han permanecido olvidados ${ }^{10}$.

A las continuas dificultades a las que se enfrentó para poder publicar, casi siempre con mutilaciones graves, a los libros censurados o denegados, a la dispersión de sus poemas por revistas y antologías, hay que añadir aún otra dificultad para la edición de sus obras completas, los poemas inéditos de los distintos libros u otros poemas sueltos que van apareciendo ${ }^{11}$.

Los inéditos que voy a mostrar forman parte de los manuscritos que el poeta entregó en la Sección de Inspección de Libros, como era preceptivo, para solicitar la tarjeta de autorización para su publicación. Están en el Archivo General de la Administración, junto a otros documentos y forman parte de los expedientes de Ángel fieramente humano, Redoble de conciencia y Ancia. Pertenecen, por tanto, todos ellos, a la primera etapa de la poesía oteriana.

Aunque he encontrado inéditos de otros libros, en esta ocasión voy a recoger únicamente los que pertenecen a su etapa existencial. Esta primera etapa, que hemos fijado entre los años 1945 y 1951, está formada por los once «Poemas para el hombre ${ }^{12} »$, que son la primera muestra del futuro Ángel fieramente humano, por Redoble de conciencia, continuación del anterior, y por Ancia porque, aunque publicado en 1958, el poeta reúne en este volumen los dos primeros libros a los que añade cuarenta y ocho nuevos poemas.

\footnotetext{
Quiero cortarte/ las manos. Esas manos que son trojes/ del hambre, y de los hombres que arrebatas.» Sus directores recibieron una serie de advertencias y protestas por parte de la censura y defenderse ante un tribunal eclesiástico. Puede verse al respecto el artículo de Eugenio de Nora, cofundador de la revista, «Recuerdos y secretos oterianos», Al Amor de Blas de Otero, op. cit., 91.

${ }^{9}$ Al lector interesado en los avatares que el poeta y la revista corrieron en esos años, remito a mi artículo «La relación de Blas de Otero con Ínsula. Una colaboración estrecha y continua», Ínsula, 676-677 (abril-mayo 2003), 58-60.

${ }^{10}$ Sabina de la Cruz, en su artículo «"Desamor”: Un poema olvidado», Ínsula, 676-677 (abril-mayo, 2003), 3-5, muestra y analiza un poema que formaba parte del original de Ángel fieramente humano que Otero presentó al Premio Adonais y que excluyó al editarlo. En mis artículos «Blas de Otero en las revistas literarias de los años cincuenta», Boletín de la Fundación Federico García Lorca, 35-36 (2005), 231-250 y «Blas de Otero en la revista Papeles de Son Armadans, Epos, XX-XXI (2004-2005), 85-100, muestro algunos poemas olvidados que no han sido incorporados a libros o antologías.

11 Jordi Amat, en «Guillermo Díaz-Plaja lee a Ramón de Basterra (1941): Un episodio de la cultura fascista española», Ínsula, 696 (diciembre 2004), 11-17, muestra un soneto inédito — de los dos que le adjuntó-, dedicado a Ramón de Basterra y fechado en agosto de 1940, que Blas de Otero le remitió en una carta fechada el 11 de diciembre de 1940.

12 Blas de Otero, «Poemas para el hombre», Egan: Suplemento de Literatura del Boletín de la Real Sociedad Vascongada de Amigos del País, 1 (enero, febrero, marzo, 1948), 3-9.
} 
El primero pertenece al manuscrito de Ángel fieramente humano ${ }^{13}$. Blas de Otero presenta el poemario al premio Adonais de 1949 y se le niega por razones extraliterarias, a pesar de que el jurado admite que era el libro de mayor calidad poética entre los presentados. Varios temas lo vertebran - la condición mortal del hombre, la angustia, la soledad, el amor-, y en él se desarrolla una lucha feroz de amor, rechazo y rebeldía entre sus dos protagonistas, Dios y el poeta. Un libro de estas características no podía pasar desapercibido y tanto los poemas de tema amoroso como los calificados con la frase de «heterodoxia religiosa», alertan a los censores ${ }^{14}$.

Al comparar el manuscrito que está junto al expediente con el original impreso, que vio la luz unos meses más tarde, constato que hay un poema que no aparece ${ }^{15}$. No fue mutilado ni prohibido, no hay ninguna mención expresa a este poema en el dictamen del censor, pero el poeta decidió no incluirlo. Sabina de la Cruz añade que este poema, titulado «Claveles», forma también parte del original mecanografiado que Otero presenta en 1949 al Premio Adonais ${ }^{16}$. Es el siguiente:

«VENCIDOS de luz, virados
a fuerza de aroma; asidos,
¡ah, sí!, pero no vencidos,
sonríen transfigurados.
Perdidos, extraviados
de amor, deshechos en mieles,
son, sin embargo, tan fieles
a sí mismos, tan clavados,
que ¡aprendan enamorados
—la clave— de los claveles!

Es, como vemos, un poema de amor, de tono alegre en el encuentro gozoso de los amantes. Este tema, permanente en la poesía de Blas de Otero, y de gran dimensión, se presenta con diversos matices a lo largo de su obra ${ }^{17}$.

Los inéditos que voy a mostrar a continuación pertenecen a Redoble de conciencia, libro que es, en sus temas y en sus formas, continuación del anterior, pero más solidario. Con él ganó el poeta en 1950, el recién creado premio Boscán en Barcelona, otorgado por el Instituto de Estudios Hispánicos.

La solicitud del permiso de publicación fue cursada con fecha 28 de septiembre de 1950. En el Archivo he encontrado una carta del Delegado Provincial de Educación dirigida al Director General de Prensa en la que le pide que agilice el trámite de su autorización. En el expediente hay también una copia mecanografiada del libro que no presenta

\footnotetext{
13 Se trata del expediente número 6296-49. El poema aparece entre «Desamor» y «Láminas».

${ }^{14}$ El proceso que sufrió este libro, los informes de los censores y otra documentación generada por el forcejeo con el editor y el Director General de Prensa, así como el dictamen final, puede verse en mi artículo citado «Blas de Otero y la censura española. Primera parte».

15 Blas de Otero, Ángel fieramente humano, Madrid, Ínsula, 1950.

${ }_{16}$ Sabina de la Cruz, Blas de Otero. Contribución a una edición crítica de su obra, Madrid, Universidad Complutense, 1983, 57.

${ }^{17}$ En la antología Blas de Otero. Poesía escogida, op. cit., XXXVIII-XLI, se puede encontrar un análisis de las constantes en el tratamiento del amor a lo largo de su creación.
} 
ninguna tachadura ni el más mínimo trazo de lápiz rojo ${ }^{18}$. Seguramente, al haber recibido un premio concedido por un organismo oficial, no fue leído o lo fue muy superficialmente por el censor. Tuvo que ser así porque algunos de los poemas que componen el libro le van a dar muchos problemas cada vez que intente su redición en libro, o aparezcan en revistas o en antologías.

Al contrastar la copia archivada con el libro impreso, constato que hay algunos poemas que no ha incluido ${ }^{19}$. No aparecen tampoco en revistas ni en antologías.

El primero es un soneto que se titula $\ll$ Revelación ${ }^{20}$ :

Levanta, por favor, descubre un poco

ese secreto, susurrantemente,

y las sedas se vuelvan, de repente,

púrpura pura y nieve roja un poco.

Recoge, eleva a pleamar un poco

esa escondida playa, ese inocente

puerto de par en par, aunque aparente-

mente sumido entre la sombra un poco.

Vuelve al revés las rosas: los celestes

cedan; los blancos, a la luz, vacilen.

Salga el secreto sin romper, intacto.

Y sobre nieve sin tocar te acuestes

y nuestros cuerpos, por amor, destilen

las más altas verdades en el acto.

Con mayor o menor intensidad pero en todos los libros, Blas de Otero ha utilizado siempre el soneto y ha formulado, además, y casi siempre en sonetos, su propia teoría sobre este tipo de estrofa, la dificultad que entraña, sus límites y márgenes. No dejó nunca de enfrentarse con el soneto, de trabajar en su extrema fijeza, de buscarle nuevos cauces, de aquilatar y medir en él su agudísimo sentido musical y, aunque trabaja otras formas, vuelve al punto de partida: el soneto.

Los sonetos endecasílabos que aparecen en las obras de su primera etapa mantienen el orden clásico de las rimas de los cuartetos y los tercetos, pero romperá con la rima clásica a partir de 1964, con Que trata de España, e introducirá combinaciones de metros y rimas.

Es frecuente en esta etapa el uso del adverbio en -mente. Incluso suele iniciar un poema con un adverbio en -mente, que se convierte en el eje sobre el que el poema gira. Este uso es frecuente en Ángel fieramente humano y Redoble de conciencia y escaso después. Incluso utiliza un tipo de encabalgamiento en -mente, como en este soneto, que ya se encuentra en Fray Luis de León, poeta al que tanto admiraba Otero.

\footnotetext{
${ }^{18}$ Se trata del expediente 5365-50 y, como el anterior, está en el AGA.

19 Blas de Otero, Redoble de conciencia, Barcelona, Instituto de Estudios Hispánicos, 1951.

${ }^{20}$ Este poema figura también en el original de Ancia, pero tampoco en esa ocasión llegará a imprimirse.
} 
Es, de nuevo, otro poema de tema amoroso. Cuando en 1986 Carlos Sahagún reúne en un volumen los Poemas de amor de Blas de Otero, la crítica cayó en la cuenta de que el amor y la mujer tienen una presencia fundamental en su obra ${ }^{21}$. En esa selección Sahagún recoge muestras de toda la trayectoria del poeta, desde sus primeros poemas amorosos (1936-1947), e incluye también algunos inéditos de sus extensos libros parcialmente publicados pero aún desconocidos en su mayor parte, Hojas de Madrid y La galerna. Sin embargo, no retoma ninguno de estos.

El segundo poema inédito de Redoble de conciencia que mostraré a continuación se titula «Arte de marear», que en el manuscrito sigue a «Que cada uno aporte lo que sepa» y refleja, como este y otros del mismo libro, el impacto causado en el poeta por la Europa en ruinas de la segunda guerra mundial, la situación posbélica, el nuevo orden mundial, las divisiones y ocupaciones territoriales, el sistema de alianzas, las tensiones y enfrentamientos entre las potencias. La desgracia mundial la afronta con cierto distanciamiento irónico no exento de amargura. Veamos el poema:

No deben tirarse los remos viejos, ni derrocar los dioses hasta que se tengan dispuestos los nuevos. Más

vale falucho de vela, que remo de galera.

Europa apenas puede con sus muertos.

América

se adentra por el hielo a mil por hora.

A contra cielo, Rusia alza una estrella.

Oriente entra en escena dando tumbos.

No nos tornemos de mares a piélagos.

Sólo Dios es bueno para barquero.

La unidad temática y formal de Ángel fieramente humano y Redoble de conciencia se refuerza al publicar ambos libros en un solo conjunto, Ancia. Cuarenta y ocho poemas nuevos intercalados y la modificación del orden original obligan a una lectura distinta de los poemas primitivos. El poeta que en 1958 vuelve a leer sus viejos poemas es un hombre muy diferente al angustiado que se expresaba en los dos primeros libros. Esta es la novedad, el sentido inaugural de Ancia.

Los poemas de cada uno de los grupos que estructuran Ancia siguen un orden cronológico de composición, dato que revela la intención de narrar una parte ya pasada de su propia vida, como una especie de mirada retrospectiva, un libro de memorias.

La primera parte del libro, dedicada al tema existencial, incluye 44 poemas, sonetos en su mayoría, y contrasta con una segunda sección cuyo tema nuclear es el amor. Pero los poemas incorporados dan una dimensión distinta al proceso amoroso.

La tercera parte lo forman una serie de «Parábolas y dezires» en la tradición gnómica de Sem Tob y Machado. Sabina de la Cruz cree que todas las «parábolas y dezires» de Ancia se compusieron en la misma época, alrededor de $1951^{22}$. Se trata de breves com-

${ }^{21}$ Blas de Otero, Poemas de amor. Selección y prólogo de Carlos Sahagún, Barcelona, Lumen, 1987.

22 Sabina de la Cruz, Blas de Otero. Contribución a una edición crítica de su obra, Madrid, Universidad Complutense, 1983, 946. 
posiciones epigramáticas donde se expresan agudos conceptos ingeniosos o satíricos, pero de una extrema concisión y con cierto tiente vanguardista que los acerca a las greguerías de Ramón Gómez de la Serna. Esta forma, narrativa en origen, tiene una doble isotopía semántica: la primera, la superficial, la anécdota; la segunda, profunda, es la transcodificación alegórica de la anécdota para la que Otero suele emplear un código religioso, frases o fórmulas litúrgicas de la tradición religiosa en la que se ha formado por medio del cual el poeta hace patente un antes y un después en su existencia, un cambio radical en la interpretación de su vida. Con ese léxico religioso suele establecer relaciones de incompatibilidad, ironía, parodia o simplemente cita refutada. Muestra en muchas de ellas un peculiar humor socarrón, que atraviesa toda su obra ya desde Redoble de conciencia y que cumple aquí un saludable papel desmitificador.

Del conjunto de las «parábolas» algunas quedaron inéditas; no fueron incluidas en Ancia y no por efecto de la censura, que puso el lápiz rojo en otras composiciones pero no en estas. Uno de esos poemillas que no pasó a Ancia, el titulado «Parábola del poeta estancado», había visto ya la luz en una revista en $1957^{23}$.

El primero de los inéditos se titula «Parabolilla». La paronomasia, que utiliza aquí como mero juego de palabras para demostrar agudeza y sentido del humor, suele ser en él habitual. Es un divertido pasatiempo que no siempre tiene una intención irónica o satírica:

$$
\begin{aligned}
& \text { LA dije: } \\
& \text { ¿por qué juegas, } \\
& \text { niña, a sostenes? }
\end{aligned}
$$

Para lo que tienes...

En otro, el titulado «INRI», desde el mismo título y con evidente ironía, alude a dos frases del lenguaje coloquial referentes al ámbito religioso para desmitificar lo que en otros tiempos tuvo como verdades absolutas.

Siempre que me he metido a redentor he salido hecho un cristo.

Hay dos más junto a los anteriores. El primero se titula «Parábola con doble fondo»:

MORIR: tocar el fondo.

a otro

$$
\text { ¿...o salir }
$$

transpuesto mar de oro?

El segundo, «Parábola del tentador»:

LE tentó el seno, y se lo comió a besos.

23 Es el siguiente: «Le dijo la vela al viento:/ -Aquí me tienes/ esperando tu santo advenimiento./ Pero no vienes.» Lo incluyó en un conjunto que tituló «Entre 1948-1955» por Blas de Otero», Cuadernos Hispanoamericanos, 91-92 (julio-agosto 1957), 157-163. 
Es en el manuscrito de Ancia en el que más inéditos he encontrado. En el sobre que contiene el expediente, hay tres grupos de poemas escritos a máquina, en papel cebolla y cogidos con una grapa. Dos contienen los poemas de sus primeros libros y en el tercero, remitido con posterioridad, ha escrito Blas de Otero de su puño y letra: «Para añadir a Ángel fieramente humano y Redoble de conciencia. Titulo general Ancia». Con este grupo de poemas añadidos podía haberse editado un libro nuevo, pero autor y editores creyeron que sería más fácil conseguir la autorización si se pedía como 2. a edición de libros que ya habían recibido la tarjeta de la Sección de Inspección y se habían publicado. Se anuncia, además en la portada, que llevará como prefacio el estudio que Dámaso Alonso había dedicado a la poesía del bilbaíno ${ }^{24}$; para que el apoyo de un poeta, crítico y lingüista de su prestigio pueda facilitar la aprobación.

Entre los inéditos de Ancia aparece el que se titula «Labio con labio en forma de salida», que copio a continuación:

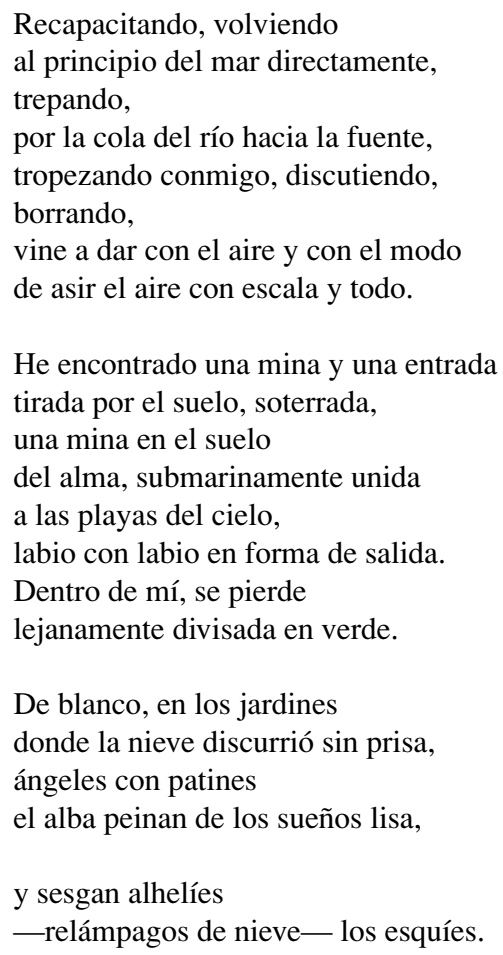

El verso libre hace su aparición en la poesía oteriana desde Ángel fieramente humano y tiene una importante representación en Redoble de conciencia y Ancia. Se trata, en general, de composiciones cuyas líneas poéticas suelen estar dentro de las que han sido clasificadas entre extensas y medias, aunque en bastantes ocasiones alternan extensas y

24 «Poesía arraigada y poesía desarraigada», en Poetas españoles contemporáneos, Madrid, Gredos, 1952 , $345-358$ 
breves. A partir de Pido la paz y la palabra se aprecia un cambio importante en su verso libre. No se trata solo de que empiecen a aparecer las primeras composiciones sin signos ortográficos, sino que la longitud de su línea poética se ha reducido también hasta llegar a En castellano, donde predominan los versículos medios y breves, para pasar a estar más equilibrados en Que trata de España.

Otro inédito de Ancia es el titulado «Hemos nacido estrepitosamente», que muestro a continuación:

Hemos nacido estrepitosamente en un mundo inclinado hacia la nada. A un lado y otro, la desidia; enfrente nada. Nada. Absolutamente nada.

Ni más ni menos que mortales. Esto me basta. Sí. Me basta ser un hombre condenado a morir. Libre de impuesto de tal o cual celeste estado. Un hombre.

Tengo que hacer. Vivir. Vivir. Y luego seguir viviendo mientras pueda. Digo vivir, volcar mi vida como un dado. Juego a ganarme la vida, dicen. Digo.

Gracias a Dios asesiné mis dioses, vedme solo, sin más quehacer que hacerme a mi gusto. Gritando a dios adioses súbitamente entristecido, inerme.

Miradme. Amigos, os lo ruego. Oídme.

Amo a todos los hombres. Vivo en medio de la calle. Callad. Callad. Oídme, oh sí, oídme llorar...

y qué remedio;

Es un poema en cuartetos endecasílabos, una forma estrófica de la que Otero hizo amplio uso en Ancia y cuyo empleo va a quedar mucho más restringido en sus siguientes libros.

El tono combativo y vital de este poema, tan cercano a otros como «Digo vivir»o «Canto primero», contrasta con los desesperados de la primera parte de este libro; es la cristalización activa del deseo de escapar de un ambiente sofocante. Deja atrás las angustias existenciales, las dudas angustiosas, su fe y sus creencias se resquebrajan definitivamente y se convierte en un hombre distinto, dispuesto solo a vivirse sin más asideros sobrenaturales. Aquí están claramente las señales de liberación de la orgullosa aceptación de la miseria y la grandeza del ser humano, «ser un hombre/ condenado a morir. Libre de impuesto/ de tal o cual celeste estado», un hombre que camina a pasos decididos del «yo» al «nosotros».

El último de los inéditos de Ancia que presento en esta ocasión se titula «No tengo/tiempo». El buen lector de la poesía oteriana reconocerá lo cercano que está este po- 
ema a los de Pido la paz y la palabra y En castellano. La negación quevedesca «No he de callar» de la «Epístola al conde-duque de Olivares», la altera y recrea, con resultados distintos, en varias ocasiones. Otero, como ciudadano español inmerso en una dictadura política, está determinado a denunciar la injusticia, a ser testigo de su tiempo aunque ponga en peligro su obra, y recurre a ese Quevedo hostil a las convenciones y creencias que determinan y jerarquizan el comportamiento de la sociedad barroca y que presenta una actitud ética frente a la realidad del mundo, un ímpetu de lucha. Este es el poema:

\author{
No tengo \\ tiempo. \\ El reloj da las horas en el centro \\ de la ciudad. No tengo \\ ochenta céntimos \\ para subir, bajar, estarme quieto \\ es más barato. Tierra en ruinas. Cielo \\ estratosférico. \\ Cuánto te echo de menos \\ Soledad Estrada, Vda. de Otero. \\ Pero no tengo \\ tiempo. Estoy dispuesto, \\ pero me falta lo que tengo: miedo \\ a callarme, por más que con el dedo \\ amenace Francisco de Silencio ${ }^{25}$. \\ Ochenta céntimos, \\ y cómo quiere usted que esté contento.
}

Es su realidad la que se le impone, una realidad que corre paralela a la historia de su patria oprimida bajo la dictadura. Los problemas con la censura se agudizan pero, a pesar de ceñido control, y parafraseando a Quevedo, no está dispuesto a callar.

Son diez poemas todos de la misma etapa, la existencial. Algunos de tema amoroso en los que se hace evidente la pasión y el componente erótico, otros reflejan la soledad del hombre, su angustia y desamparo ante la limitación del destino de un ser mortal, que asume su destino. En otros irrumpe el tema histórico, la tragedia colectiva de la guerra y su compromiso con el hombre. El virtuosismo con que maneja el soneto, los recursos expresivos, a los que saca tan sorprendente y eficaz rendimiento, el distanciamiento irónico tan próximo a las estéticas de vanguardia, son algunas de las características de su poesía que se detectan también en estos poemas inéditos.

\footnotetext{
${ }^{25}$ Quevedo es un poeta de honda huella en la poesía oteriana. En la entrevista que le hizo Luis Suñén «Blas de Otero con los ojos abiertos», Reseña, 88 (septiembre-octubre 1975), 11, declaró el poeta: «en mi etapa existencial influyó sobre todo el Quevedo de los sonetos». La negación quevedesca a la que acabo de aludir, se repetirá en varias ocasiones: en «No cuando muera he de callar» de Ancia, en «Censoria» de En castellano o en «No quiero que le tapen la cara con pañuelos» de Que trata de España.
} 